\title{
500 DÍAS DE HISTERIA... DIGO, CON ELLA
}
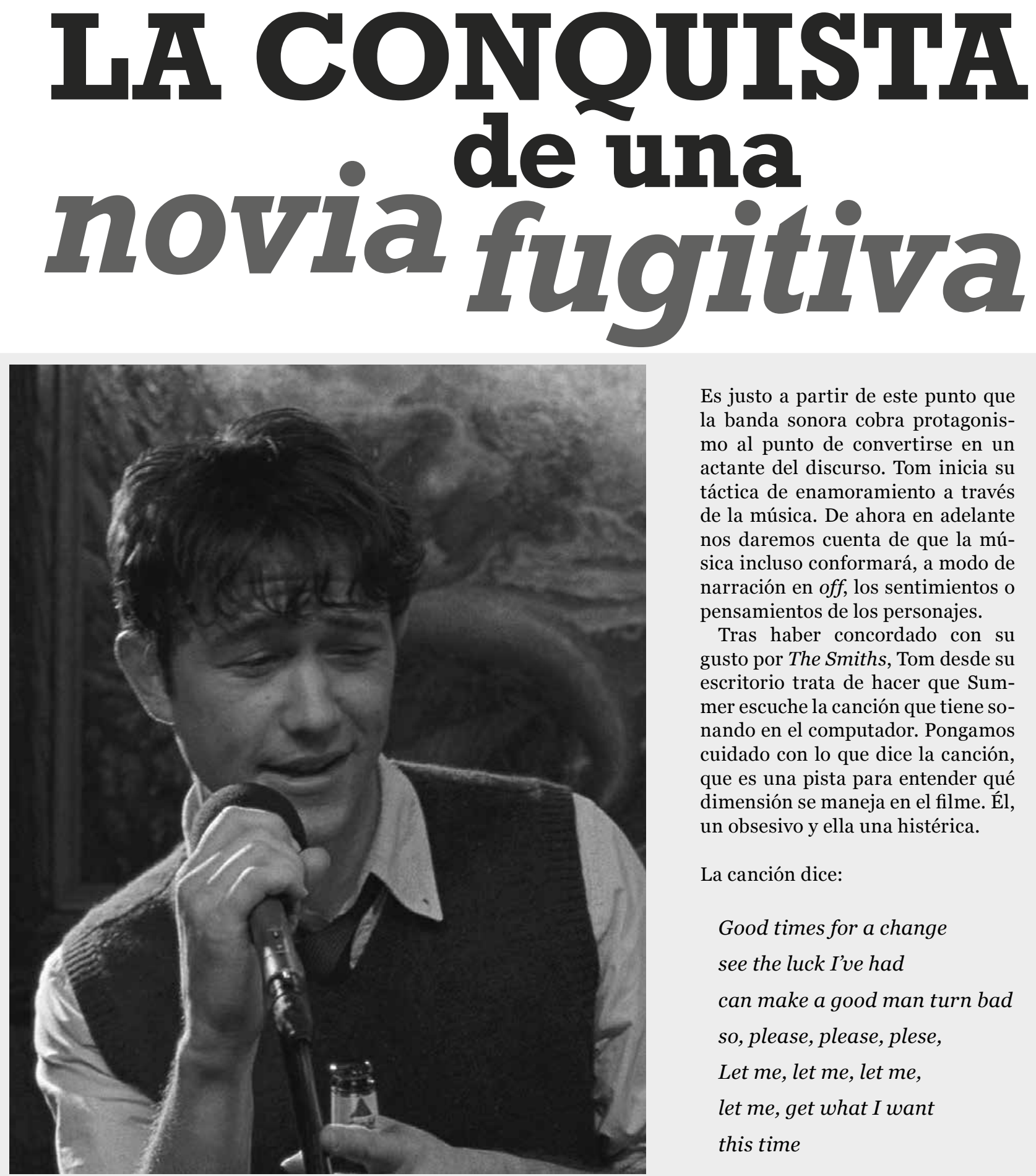

Es justo a partir de este punto que la banda sonora cobra protagonismo al punto de convertirse en un actante del discurso. Tom inicia su táctica de enamoramiento a través de la música. De ahora en adelante nos daremos cuenta de que la música incluso conformará, a modo de narración en off, los sentimientos o pensamientos de los personajes.

Tras haber concordado con su gusto por The Smiths, Tom desde su escritorio trata de hacer que Summer escuche la canción que tiene sonando en el computador. Pongamos cuidado con lo que dice la canción, que es una pista para entender qué dimensión se maneja en el filme. Él, un obsesivo y ella una histérica.

La canción dice:

Good times for a change see the luck I've had can make a good man turn bad so, please, please, plese,

Let me, let me, let me, let me, get what I want this time 
$\mathrm{Al}$ igual que Ulises en La Odisea, Tom deja ver con cierta ignorancia que actúa en la atracción fatal de las sirenas, que en este caso es Summer. Ella quería atrapar a Tom, pero de ningún modo se muestra impresionada por él; él no es objeto de su deseo. Y es que la tensión del filme, o mejor dicho el proceso de enamoramiento, el deseo del Otro inicial es el horror en el sujeto angustiante. Esta angustia surge porque el deseo del Otro permanece como un enigma para el sujeto; él nunca puede llegar a saber qué clase de objeto es para el Otro.

Por eso, que coloque esta canción es la petición ante la angustia de no saber qué pasará con ella, si realmente ella está enamorada de él, si quiere una relación, y principalmente qué tipo de relación tendrán. Por eso, la canción de The Smiths es la súplica [let me, what I want] de Tom para pedirle permiso para poder meterla en su fantasma, para poder generar una relación. Sin embargo, a partir de esto dos perfiles se vislumbran con mayor facilidad. ¿Es acaso Tom un obsesivo y Summer una histérica?

Mientras que para la histérica es insatisfactorio todo objeto del deseo, ese deseo aparece como demasiado satisfactorio para el obsesivo y, por tanto, él debe resguardarse por todos los medios con el encuentro del objeto (Salelc, 2002, pp. 80). La histérica, eludiendo constantemente al Otro, escurriéndose como objeto, alimenta la falta en el Otro. Ella quiere ser el objeto definitivo y final del deseo del Otro y, a la vez, impide que esto suceda; al hacerlo mantiene insatisfecho su deseo. El obsesivo, en cambio, sostiene un deseo imposible, y lo hace así para negar el deseo del Otro.

Comprobemos nuestra hipótesis. Las escenas que siguen a la declaración de Tom -vía la canción de The Smiths-, nos muestran que realmente Tom dice que está enamorado, que quiere el amor, que Summer es la indicada; sin embargo, puntualicemos. Tom nunca hace nada por obtener el amor, solo lo dice, lo enuncia, pero ċrealmente lo quiere? ¿Y si lo quiere, por qué nunca hace nada por conseguirlo? En ningún momento del filme Tom es agente de sus acciones. Recordemos que en las conversaciones que tiene con los amigos, él sostiene que la soledad está subestimada.

Aunque se nos presenta como un hombre que teóricamente estaría en posición femenina, este hombre de lo único que padece es de su fantasma, que si bien no es el típico hombre que rehúsa el amor, este sujeto está más cerca del personaje principal de La ventana indiscreta (1954); no le teme a una relación pero sí al compromiso. Nótese que en concordancia con Zygmunt Bauman (2003), esta pareja entiende por amor no solo el brillo del petit objet a sobre la relación, sino como conexiones de las que pueden deshacerse rápidamente. Por eso es que la relación, que ella comienza,

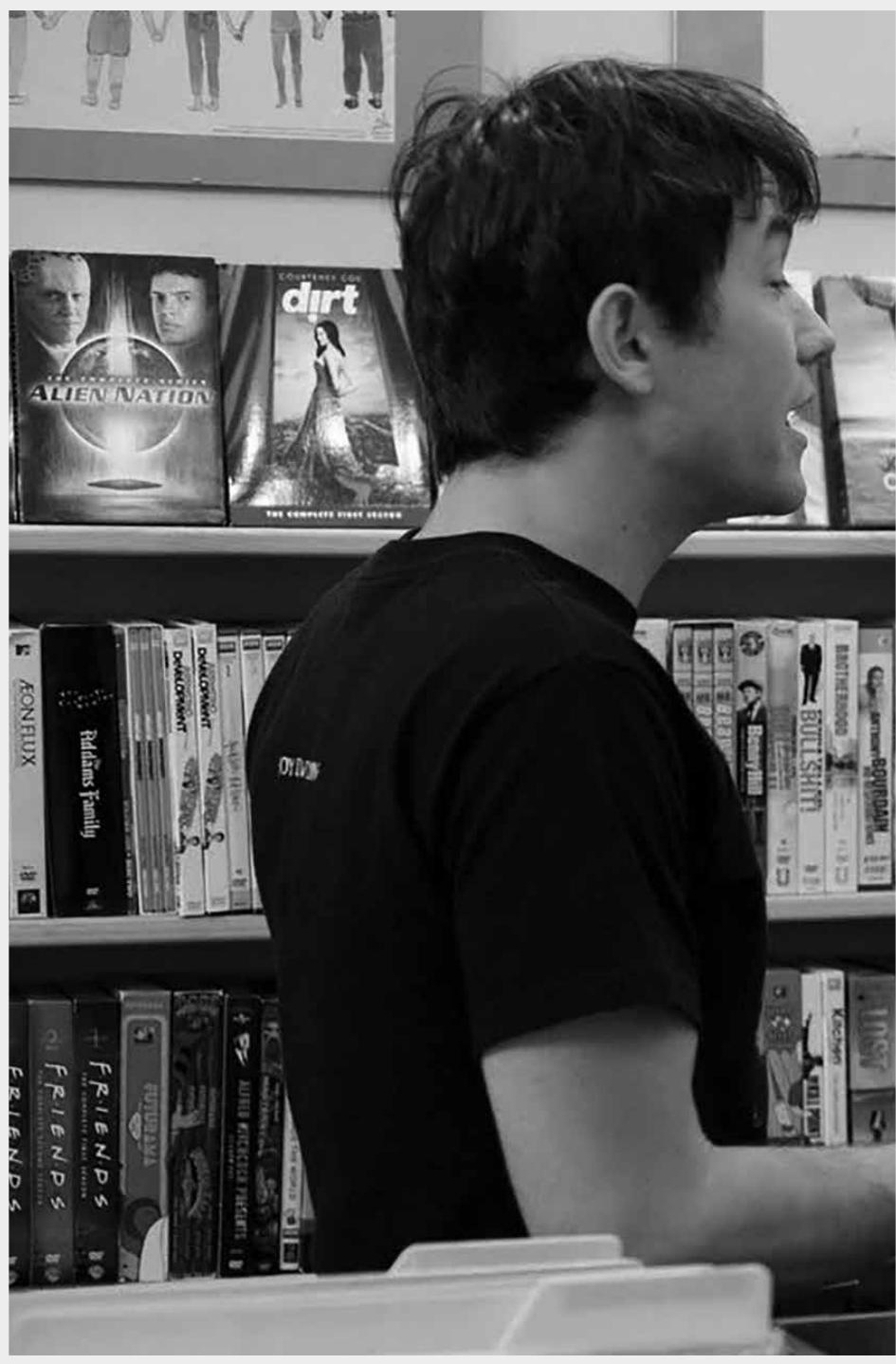

funciona. Aunque en el filme veamos que -teóricamente- Tom no está del todo de acuerdo con esto, en realidad el juego de Summer lo único que hace es reafirmar el fantasma de la mujer que quiere todo pero sin compromisos.

Por eso en la escena del karaoke, que más se asemeja a una talking cure, cada uno muestra su fantasma. El primero, McKenzie (con el que abre la escena), dice -cantando- que todo cowboy canta una triste canción y toda rosa tiene su espina. ¿Qué nos está diciendo? Básicamente, un hombre busca a una mujer porque está solo, y cada una tiene diferentes problemas, no son fáciles de tener, pero finalmente siempre terminan yéndose con el cowboy; algo semejante a Marco Tulio Gutiérrez cuando sostuvo que "todas las mujeres dicen no, pero luego dicen que sí".

Cuando termina la canción, Summer sube al escenario y con la prosa de Nancy Sinatra afirma que ella tiene algunos problemas, pero no dudarán que se quedará tendida en la hierba y pronto desaparecerán porque 


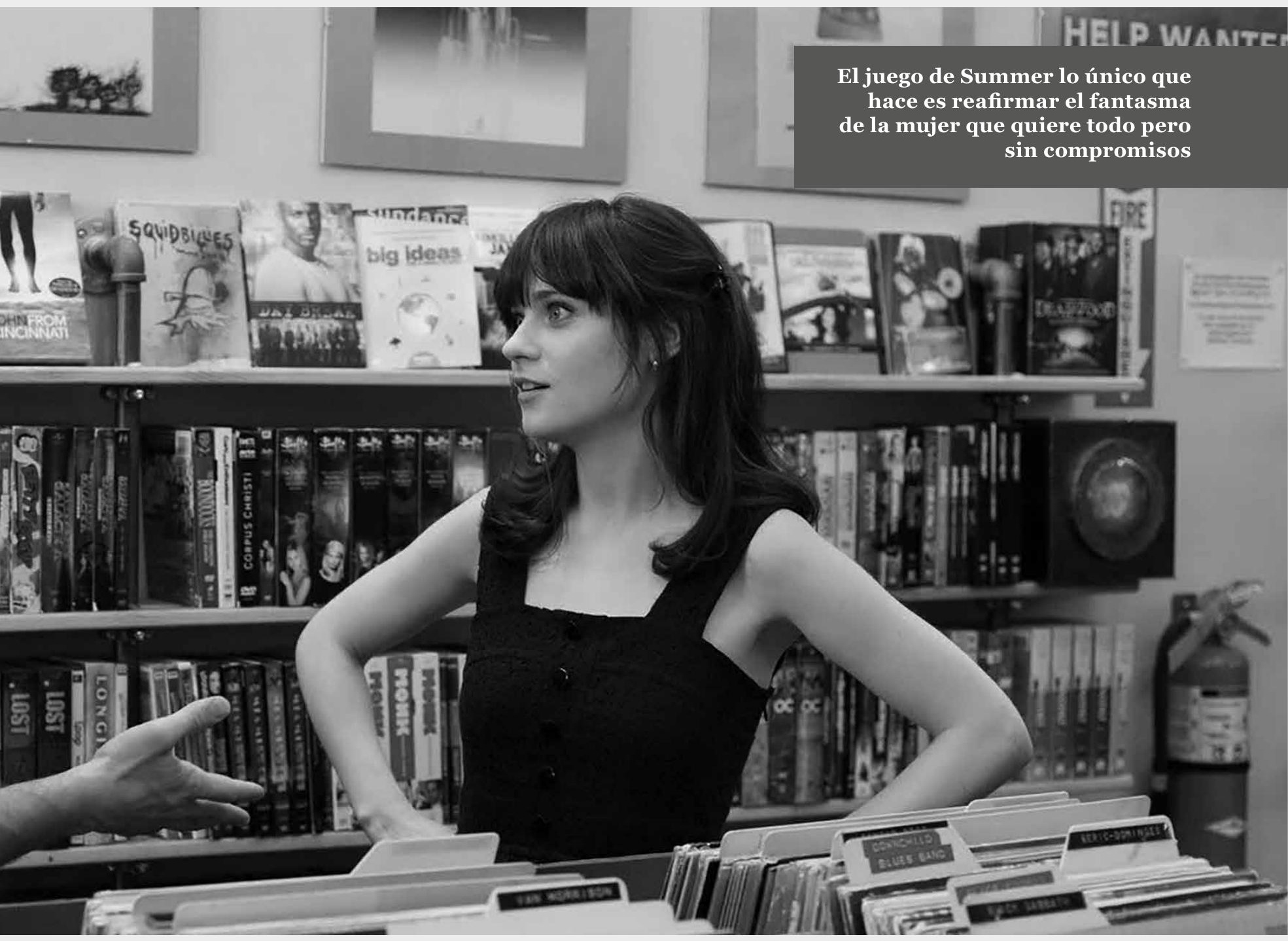

ella está en dulcelandia [sugar town]. En efecto, ella reafirma lo dicho anteriormente. Ella ha llegado a ese lugar solo para divertirse. Los problemas que tuvo se irán con el paso del tiempo, porque ella está en Sugar town, que podríamos traducirlo como el país de la dulzura o, tal vez, de la diversión.

Esto queda aún más explícito en la escena contigua, cuando McKenzie, Tom y Summer están sentados tomando una cerveza. Ella empieza diciendo que quería cantar Born to run, que podríamos traducirla como nacida para correr o huir; sin embargo, no la tienen. Es decir, ella quería darse a conocer con las cosas claras. Ella, en su calidad de histérica, "quiere ser el objeto siempre elusivo del deseo del Otro, pero rechaza ser el objeto del goce del Otro" (Salelc, 2002, pp. 82). No quiere ser tan solo un objeto parcial que el Otro disfruta sino algo más, el inalcanzable objeto del deseo.

El diálogo que sigue lo explicita aún más. McKenzie pregunta si ella tiene un novio. Ella responde categóricamente que no quiere. Él, incrédulo, se burla un tanto de lo dicho porque no le cree; para él (el cowboy) una mujer siempre necesita de un macho, por eso lo busca con desesperación. Así, cuando ella sostiene que una mujer puede ser feliz siendo libre e independiente, la respuesta de McKenzie es preguntarle si es lesbiana; es decir, si ella está en posición masculina, al ser Sujeto. Ella niega ser lesbiana, y argumenta que no se siente cómoda siendo la novia de alguien, o siendo algo de alguien, es decir, ser que su goce esté inscrito en la palabra; para ella, eso es intolerable. McKenzie confiesa que no entiende ni una palabra de lo que dice. ¿Por qué? Porque claramente ella tiene la figura de una mujer, el atractivo de una mujer, pero no se "comporta como una mujer”. Es decir, Summer horada el fantasma de McKenzie, lo perfora de tal modo que él no la concibe como una mujer, por eso tras un par de líneas más de Summer, sentencia que ella es un tío [she's a dude]. 


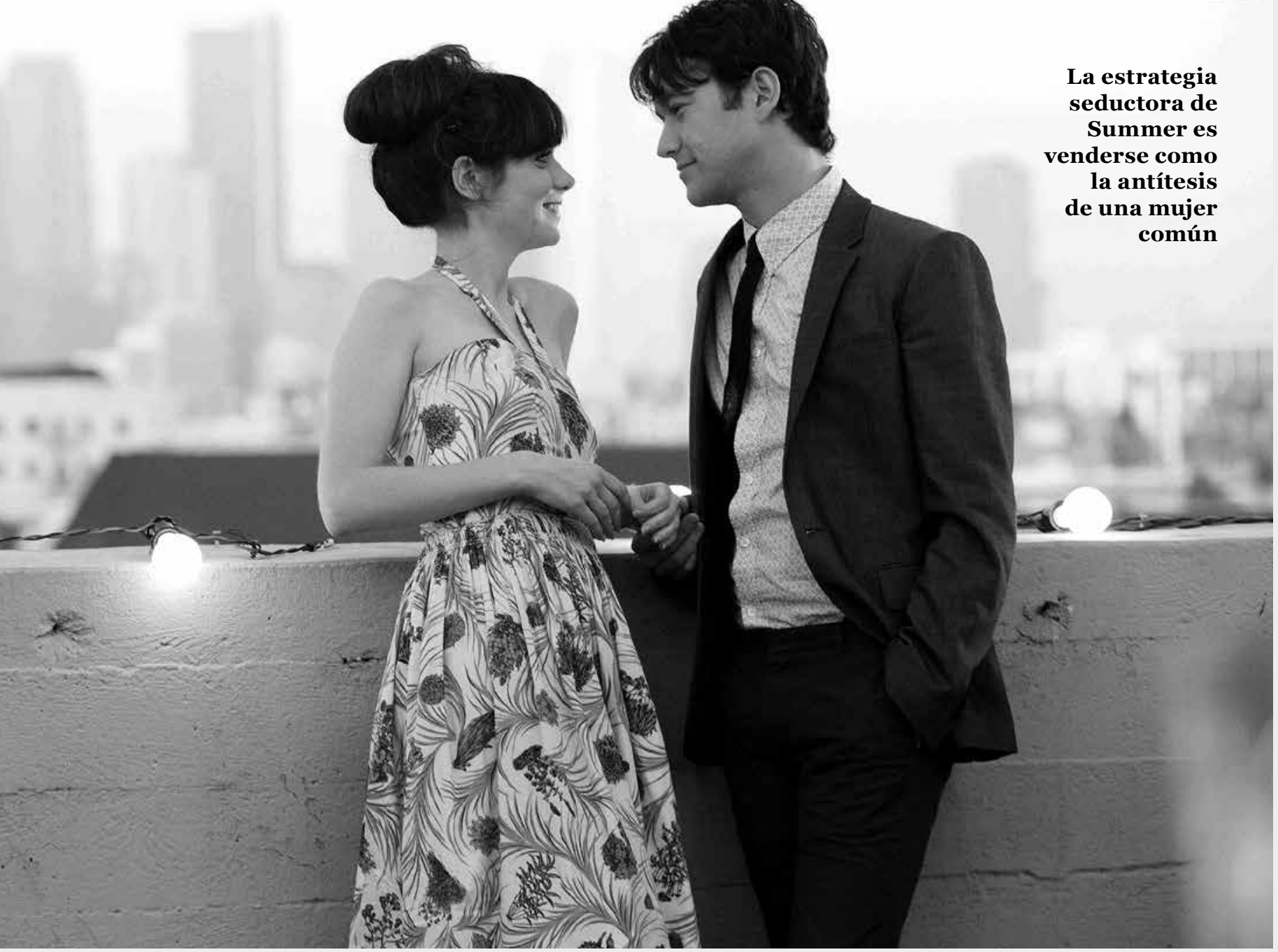

Habíamos dejado suelta la idea de su llegada a Sugar town. Para ella esta ciudad, donde ocurre la diégesis del filme, lo es. Esto se expone en la misma escena analizada en el párrafo anterior. Ella sostiene que no quiere tener ninguna relación porque son un enredo, la gente sale herida, son jóvenes, viven en una de las ciudades más hermosas del mundo, deben divertirse lo más que puedan.

Veamos que esta es la escena que termina por introducir a Summer en el fantasma de Tom, es lo que da pie a la relación de ambos (aunque teóricamente no parezca una unión). Tom, aunque dice que él cree en el amor -y ciertamente lo concibe- no cree en el compromiso. Por eso la pregunta que le hace no es para convencer a Summer de que su argumento es errado, sino para ratificar que eso que ella piensa no es solo de boca para afuera.

$\mathrm{Y}$ es que la histérica se enmascara como mujer fálica con la intención de cubrir la falta en el Otro, de comple- tar al Otro. Pero dado que su intento siempre fracasa, necesita reincidir en su estrategia seductora una y otra vez. Mediante la seducción trata de despertar el deseo del Otro hacia ella, algo que, por supuesto, jamás encontrará satisfacción. Si nos ponemos en los pies de Tom podríamos decir: iqué mejor mujer que esta! Porque la estrategia seductora de Summer es venderse como la antítesis de una mujer común. El filme concuerda con ello y él canta que ha estado esperando por mucho tiempo, por eso here's come your men. Ella, sentada en el público, lo aplaude, en signo de "este bobo ya cayó", porque, recordemos, es ella la que inicia la relación y a su vez la que le pone fin.

La escena termina con la clave que rige en este filme. McKenzie sube nuevamente a escenario y afirma en su canto que está orgulloso de ser americano porque es el lugar donde al menos sabe que es libre. ¿No es acaso que en esta parte la soltería se presenta como una nueva exclusión para la mujer? "Si en el pasado ella queda 
excluida de la vida pública, ahora se le ve excluida de la vida privada" (Ubilluz, 2012, pp. 96).

Ahora bien, la histérica interroga incesantemente el deseo del Otro mientras que el obsesivo no quiere saber nada de ese deseo. Él busca escapar de las situaciones que conllevarían a la confrontación o que pudiesen de algún modo perturbar su equilibrio. De ese modo el encuentro con el Otro deseante llega a ser la cosa más espantosa para él. Por ello, no es gratuito que la escena termine con ella preguntándole si él gusta de ella. Él se turba pues, como buen obsesivo, esta escena no está en su plan, nunca se la ha imaginado, o al menos con tanta prontitud; por el contrario, ella lo saca de su zona de confort, hace tambalear la forma de goce del obsesivo.

Hacia este punto es fundamental invertir la lectura frecuente que se tiene de Summer. Habitualmente se dice que es una mujer mala, pérfida, que lo traicionó. Sin embargo, observemos que, en principio, es ella la "traslúcida” en su petición afectiva. Ella desde ese primer momento propone que su relación sea de amigos, y que quiere que se mantenga así. Tom, decepcionado, entiende que el significante amigos hace referencia a lo que él entiende por amigos, es decir, alguien con el que habla sobre sus fantasmas, pero con el que no tiene coito ni atracción. Sin embargo, Summer -ya que su goce no está atrapado en el lenguaje - trata de hablar en clave de Tom para que pueda entender lo que ella siente. Y es que, si bien ya lo sabemos por el resto que nos deja el objeto $a$, la petición de ser amigos no significa que exista una barrera en el orden de lo sexual. Por el contrario, para Summer, ser amigos implica lo que veremos a continuación: relaciones sexuales, compartir tiempo, pero sin compromisos.

Démonos cuenta que el filme se erige sobre el malentendido. Ella propone desde el comienzo hasta el fin su posición, por el contrario, Tom es el que rompe con el pacto. Tom, por tanto, es el que destruye la relación cuando resquebraja la conexión que tienen queriendo dar nombre al goce femenino, y que en el filme se le da el nombre de relación.

\section{On l'a dit femme on le diffame}

Este concepto lacaniano nos permite cerrar nuestro escrito, ya que el problema de este malentendido radica en la obsesión de Tom por decirla mujer y mal-decirla. Lacan juega con estos términos para decir que cada vez que desde la postura masculina se quiere nombrar el goce femenino, se maldice a la mujer. Y no solo porque implique un insulto, sino que mal-dice (o lo dice mal) qué es lo que quiere una mujer, porque, recordemos, estos filmes tienen en el público femenino mayor atracción. De ese modo, la pregunta que nos podríamos hacer es, ¿̇por qué es que esto apela a la mujer y más bien se convierte en tedioso para el hombre?

Porque es claro que está enunciado desde la postura femenina en donde la mujer es mal-decida (o di- cha) por el goce fálico, ya que justamente, como anota Lacan, es este goce particular femenino aquel que excede totalmente el lenguaje, y por tanto, darle un significante (un nombre) termina por convertirse en un problema. Choque de goces. Sí, pero no solo se trata de eso sino de cómo es lógico que el final de esta película sea así, en donde ella no termina con Tom, pues él quiere algo que ella, al fin y al cabo, no está dispuesta a ceder.

En síntesis, que el filme termine con la curiosa casualidad de encontrar a una chica que tiene también nombre de estación, nos deja en claro que las relaciones de parejas son estacionarias, están compuestas por un tiempo de caducidad, un par de meses, o quinientos días, pero al fin y al cabo siempre terminan por ser circulares, cíclicas, y por tanto, se vuelve o se busca aquello que produjo goce al sujeto. Por eso ya lo decía Julio Iglesias, el hombre es el único que tropieza de nuevo (dos veces e infinitas veces) y con la misma piedra... aunque para nosotros será con la misma histérica.

\section{REFERENCIAS BIBLIOGRÁFICAS}

Altman, R. (2000). Los géneros cinematográficos. Barcelona: Paidós.

Baudrillard, J. (1978). Cultura y simulacro. Barcelona: Kairós.

Bauman, Z. (2003). Amor líquido. Acerca de la fragilidad de los vínculos humanos. Buenos Aires: Fondo de Cultura Económica.

Bauman, Z. (2006). Vida líquida. Buenos Aires: Paidós.

Chion, M. (1985). Le son au cinéma. Paris: Éditions de l'Etoile.

Lacan, J. (1998). Le séminaire, livre V: Les formations de l'inconscient. París: Éditions du Seuil.

Mcgowan, T. (2007). The Real Gaze. Film Theory After Lacan. Nueva York: State Univesity of New York Press.

Nasio, J. D. (1996). El libro sobre el dolor y del amor. Barcelona: Gedisa.

Neale, S. (2000). Genre and Hollywood. Londres / Nueva York: Routledge.

Salelc, R. (2002). (Per)versiones de amor y de odio. México D.F.: Siglo XXI.

Stam, R. (1992). Reflexivity in Film and Literature: from Don Quixote to Jean-Luc Godard. Nueva York: Columbia University Press.

Todorov, T. (1977). The Poetics of Prose. Oxford: Basil Blackwell.

Ubilluz, J. C. (2012). La pantalla detrás del mundo. Ficciones fundamentales de Hollywood. Lima: Red para el Desarrollo de las Ciencias Sociales.

Žižek, S. (2003). Las metástasis del goce. Seis ensayos sobre la mujer y la casualidad. Buenos Aires: Paidós. 